\title{
ASSISTÊNCIA DE ENFERMAGEM NO HOSPITAL-DIA EM SAÚDE MENTAL DO JARDIM LÍDIA 1
}

NURSING ASSISTANCE AT JARDIM LÍDIA MENTAL HEALTH DAY-HOSPITAL.

Sibele dos Santos Souza ${ }^{2}$

RESUMO: A autora relata sua experiência nesta instituição com característica não manicomial. Aponta que o programa de tratamento intensivo é possivel para pacientes que possam permanecer em casa parte do tempo. Elabora atividades individuais e valoriza as terapêuticas grupais visando reintegrar o paciente à sociedade e proporcionar - Ihe a possibilidade de uma melhor qualidade de vida.

UNITERMOS: Hospital-dia - Enfermagem psiquiátrica - Saúde mental.

ABSTRACT: The author describes her experience in this no insane asylum characteristics institution. She points the possibility of intensive treatment for patients who can stay home part-time. She elaborates individual activities and group therapy in order to reinstate this patient to the society providing them a better life quality.

KEYWORDS: Day-hospital - Psychiatric nursing - Mental health

\section{INTRODUÇÃO}

Durante dezoito anos de trabalho como enfermeira sempre me perguntei se não haveria uma forma diferente de assistir o paciente e sua família, em que estes não fossem passivos recebedores de cuidados de enfermagem e sim participantes do processo de tratamento e em que os auxiliares de enfermagem não fossem meros cumpridores de ordens, mas participassem do processo de elaboração do plano de assistência de enfermagem.

Embora esta questão me perseguisse, eu me vi, muitas vezes, cumprindo um papel de seguidora da prescrição da instituição e da profissão, no seu sentido mais tradicional. No entanto, esta condição me colocava em uma oposição do que queria. Nas tentativas de mudança que usava, desistia frente às primeiras dificuldades e, como defesa, acusava a estrutura. Com isso não desconsidero que o contexto histórico e conjuntural das instituições hospitalares e do próprio processo de trabalho da enfermagem interferem nos processos de tentativa de mudança.

${ }^{1}$ Trabalho apresentado no $48^{\circ}$ CBEn. - São Paulo - SP, outubro de 1996.

2 Enfermeira Psiquiátrica no Hospital-Dia em Saúde Mental Jardim Lídia, pós-graduada em Enfermagem Psiquiátrica e em Saúde Mental pela EEEPM, mestranda em enfermagem pela EEUSP. 
A saída para a minha inquietação fui buscar na enfermagem psiquiátrica, área que me chamou a atenção desde a graduação. No decorrer da especialização em Enfermagem Psiquiátrica (1991), tomei contato com os movimentos de reforma da Saúde Mental e adquiri conhecimentos teóricopráticos que me colocaram em uma perspectiva de viabilizar mudanças no processo "de cuidar" do paciente, bem como de trabalhar com a equipe de enfermagem.

Em 1992 surgiu a grande oportunidade, trabalhar em um Hospital-Dia em Saúde Mental.

\section{O HOSPITAL DIA EM SAÚDE MENTAL}

Antes de falarmos da incrementação de hospitais-dia, vamos recordar pouco da história da "atenção" ao doente mental no Brasil.

Segundo Schechtman' (1996), no início da década de 90, a assistência ao doente mental, no Brasil, era de má qualidade. Afirma que a violação dos direitos humanos e da cidadania dos pacientes internados em hospitais psiquiátricos sempre foi patente e visível. Toda essa problemática decorria de diversos fatores, sendo o primordial a própria lógica de exclusão do modelo assistencial vigente. Houve como conseqüência a fixação de um modelo manicomial e segregador, excluindo a saúde mental das metas priorizadas. Ressalta ainda que, na década de 70 , ocorreu o chamado processo de psiquiatrização, caracterizado pelo crescimento exagerado do número de hospitais psiquiátricos privados, decorrente da exacerbação dos problemas sociais. No final dos anos 80 , o Brasil tinha 313 hospitais psiquiátricos, sendo 259 privados e 54 estatais. A democratização do País possibilitou à saúde, após grandes debates, avanços para uma reforma sanitária. Em 1990, foi aprovada uma nova Lei Orgânica de Saúde - o Sistema Único de Saúde, prevendo o bemestar social. A saúde mental se beneficia com o Movimento Nacional da Luta Antimanicomial.

A Assessoria de Saúde Mental da Secretaria Municipal ${ }^{5}$, mediante uma proposta de operacionalização da atenção à saúde mental nos diversos serviços, passou a transformar, paulatinamente, a política municipal de saúde mental na cidade de São Paulo.

Neste contexto, houve a implantação de um modelo substitutivo de atenção em saúde mental, na rede pública, com característica não manicomial, combatendo uma das mais graves violências institucionais na saúde e na própria sociedade. O modelo custodial, com seus grandes hospitais psiquiátricos, exclui e segrega os indivíduos em um processo de cronificação da doença em lugar de tratar e reabilitar as pessoas.

No afã de encontrar soluções para a saúde mental no Distrito do Campo Limpo, conta Figliola (s/d) que surgiu a formação de um grupo de trabalho, com profissionais da enfermaria psiquiátrica do Hospital Geral e das unidades básicas de saúde da região mantidas pela Prefeitura do Município de São Paulo. 
Em 1991, as unidades básicas de saúde do Jardim Lídia e do Jardim Mitsutani funcionavam em casas alugadas. Com a construção de novos prédios pelo Governo do Estado de São Paulo, foram iniciadas as discussões sobre onde seria o melhor lugar para a instalação de um hospital-dia. Finalmente optaram pela instalação junto a Unidade Básica de Saúde do Jardim Lídia. Em maio de 1992, ocorreu a inauguração oficial, com participação dos atendidos e comemoração da Semana de Luta Antimanicomial.

Destaco que o funcionamento do hospital-dia anexo a uma unidade básica de saúde é vantajoso porque os pacientes psiquiátricos também têm problemas clínicos, facilitando um atendimento global. Esta situação colabora para uma sensível diminuição do preconceito da sociedade em relação ao doente mental, auxiliando na sua reinserção na sociedade.

Em maio de 1996, o Hospital-Dia em Saúde Mental do Jardim Lídia, que até então era gerenciado pela Secretaria Municipal de Saúde, através do Distrito de Saúde do Campo Limpo, passou a ser administrado por uma cooperativa que presta serviços à Prefeitura do Município de São Paulo, mediante a implantação do Plano de Assistência a Saúde.

O Hospital Dia em Saúde Mental do Jardim Lídia, desde sua criação, tem alcançado resultados qualitativos no atendimento do doente mental. Substitui os longos períodos de internação por um tratamento que não isola os pacientes de suas famílias e comunidade, envolvendo os familiares em seu atendimento e oferecendo a estes a atenção necessária, fatores que ajudam na sua recuperação e em sua reintegração social.

Este serviço de atenção à saúde mental propõe-se a assistir indivíduos com quadros mentais graves (psicóticos e neuróticos), em regime de internação parcial, no periodo diurno. Foi criado para atender adultos em quadro sub agudo, em condições de permanecer parte do tempo em casa, participando do convívio familiar à noite e nos finais de semana e que possam, durante o tratamento, ir e vir de suas residências, sem exporem os outros e a si mesmos a riscos de vida.

Nitta ${ }^{4}$ preconiza o diagnóstico precoce, tratamento e acompanhamento dentro de uma rede de serviços. Desta forma, os pacientes, para os quais haja indicação de atendimento intensivo, porém, não necessitem de internação integral, deverão ser encaminhados da enfermaria ou da emergência psiquiátrica do Hospital do Campo Limpo e das unidades básicas de saúde para o HospitalDia.

O limite de vagas está atualmente estabelecido em 30 pacientes internados. A população coberta pelo serviço compreende maiores de 18 anos.

Este' hospital está aberto durante cinco dias da semana, de segunda a sextafeira, das 7 às 18 horas. Consta do quadro de funcionários, atualmente, um médico clínico, dois médicos psiquiatras, uma terapeuta ocupacional, uma assistente social, uma psicóloga, uma enfermeira, quatro auxiliares de enfermagem e equipe de apoio, constituída por copeira, porteiro, auxiliar técnico administrativo e faxineira. Além do atendimento individual, é dada ênfase às 
terapêuticas em grupo. As atividades pragmáticas valorizam as relações interpessoais e o desenvolvimento de habilidades sociais, principalmente no âmbito familiar. Estas atividades também ajudam no tratamento medicamentoso, caso o paciente dele necessite. Na dinâmica dos atendimentos grupais, são utilizados os potenciais existentes em todas as pessoas, inclusive nos pacientes, os quais não assumem coordenação, mas podem ser destacados na ajuda.

O paciente receberá alta em função dos objetivos de cada tratamento, mediante critérios que devem ser realizados de forma integral. A alta deve ser parte inerente do processo de tratamento e não constitui uma entidade à parte.

O programa deve ser flexível à medida que o paciente vai se recuperando. Alguns pacientes permanecem em atendimentos de seguimento arnbulatorial, individuais ou grupais, mesmo após a alta. O processo de desligamento é trabalhado com cuidado até a inserção do paciente em outros serviços.

A assistência de enfermagem, no início, limitava-se à ministração e orientação dos medicamentos que seriam tornados à noite e nos finais de semana e, observação do comportamento e dos sinais e sintomas físicos. Decidimos ampliar ao máximo estas ações e para tanto buscamos embasamento teórico.

Segundo Loyola (1987), "a enfermagem assume responsabilidades de se solidarizar com pessoas, grupos, famílias e comunidades, com o objetivo de mobilizar a cooperação de cada ser humano para conseguir conservar e manter-se em estado de saúde". A assistência de enfermagem psiquiátrica é pautada no entendimento de que o papel da equipe de enfermagem é o de agente terapêutico, e que a base desta terapia é o relacionamento estabelecido com o paciente, a partir da compreensão do significado do seu comportamento. Por isso, os auxiliares de enfermagem têm sido orientados e recebido a supervisão necessária para que estas funções sejam amplamente alcançadas.

Segundo Travelbee ${ }^{9}$, é fundamental para a atuação da enfermeira a observação do paciente e a comunicação da mesma aos outros membros da equipe.

Arantes $^{1}$ afirma ser a observação completa e objetiva, elemento indispensável para a identificação das necessidades básicas do paciente e planejamento da assistência individualizada.

O planejamento das atividades dos pacientes, a partir de observações e avaliações, leva em conta a doença, as necessidades e peculiaridades do doente e da sua situação social durante a admissão. O plano de cuidados específico para cada paciente pode ser modificado diariamente, de acordo com as necessidades percebidas. Através de reuniões semanais, são discutidos casos de pacientes e é elaborado o planejamento da assistência de enfermagem.

Kurcgant $^{3}$ afirma que a educação em serviço deve ampliar os conhecimentos, capacitar para atuação adequada e promover o crescimento pessoal e profissional. 
Com o intuito de desenvolver uma melhor qualidade e assistência de enfermagem, o treinamento para os recém admitidos e programas de educação em serviço têm sido priorizados.

A assistência de enfermagem procura desenvolver no paciente o auto cuidado, resgate da dignidade do indivíduo, auto-estima, auto-realização, percepção das próprias necessidades básicas, assunção de responsabilidades e mudanças no comportamento quando inadequado.

Em busca de alcançar o que foi exposto, a equipe de enfermagem, com outros profissionais, desenvolve grupos terapêuticos e de socialização. Estes grupos têm por objetivos estimular o interesse e independência para a atividade de vida prática e diária, organização pessoal, cooperação e produção grupal, relacionamento interpessoal, auto-estima, iniciativa, criatividade, expressividade, exercício físico e mental, coordenação motora, interesse e observação, habilidades manuais e perseverança .

A enfermeira coordena os grupos de Jornal, Expressão Gráfica, Cuidados Pessoais, Enfermagem, Música e Alta; atua como coterapeuta nos grupos de Reencontro, Expressão Corporal, Vídeo, Oficinas Terapêuticas e Reunião com Familiares.

Os auxiliares de enfermagem coordenam os grupos de Artes, Atividade Vocal, Jogos e Recreações; atuam como auxiliares terapêuticos nos grupos de Jornal, Cuidados Pessoais, Culinária, Criações, Horta, Jardinagem, Vídeo e Música. Ressalto que a coordenação de grupos é feita por auxiliares que têm preparo adequado para tal.

Os grupos acontecem mediante uma grade de atividades que determina hora, dia e profissionais envolvidos na atividade.

O plano de tratamento individualizado indica os grupos em que o paciente participará. No entanto, procura-se desenvolver também o sentimento de grupo, tarefa nada fácil.

Cita-se como exemplo o Grupo de Música, em que são incentivadas as expressões dos sentimentos através da fala, do corpo e da música. É estimulada a coordenação vocal, rítmica e corporal. Intenta -se facilitar o relacionamento interpessoal. As pessoas escolhem músicas, cantam, acompanham com instrumentos rítmicos artesanais e falam sobre o significado das letras ou sobre o sentimentos que emergiram ao cantar. Alguns dançam. 0 acompanhamento é feito pelo teclado e às vezes temos alguém ao violão.

Procura-se tomar o ambiente agradável e incentiva-se o companheirismo. Neste grupo também planeja-se festinhas, ensaios e apresentações. Às vezes faz-se "karaokê" ou "show de vale tudo". Invariavelmente nestas comemorações participam ex-pacientes. Mesmo após a alta alguns pacientes costumam, esporadicamente, aparecer neste grupo para rever os amigos .

O grupo acontece às sextas-feiras à tarde e pressupõe-se que, por ser uma atividade mais agradável, ela pode proporcionar sentimentos mais alegres. $\dot{E}$ evidente que sentimentos de raiva, ódio, tédio, saudade e tristeza podem aflorar nesta atividade. Todavia, em especial nos últimos momentos, são induzidos sentimentos agradáveis mediante músicas escolhidas. Então, os pacientes poderão, mais tranqüilos e bem humorados, retornarem aos seus lares, para permanecer com os familiares durante o fim de semana. 
A prestação de serviços no Hospital-Dia em Saúde Mental do Jardim Lídia tem proporcionado satisfação pessoal e profissional à equipe de enfermagem que optou por assistir o doente mental mediante esta proposta inovadora, contribuindo para alcançar os objetivos propostos e expostos anteriormente.

O paciente, usando medicamentos, pode ter uma meihor qualidade de vida e se reintegrar à sociedade da melhor maneira possível, e para tanto procura nossos serviços e solicita atenção, estímulo e orientação. Enfim, ele vem em busca de algo que a enfermagem pode oferecer-lhe.

\section{REFERÊNCIAS BIBLIOGRÁFICAS}

1. ARANTES, E. Observação de Comportamento de Pacientes Internados em Hospital Psiquiátrico. R. Bras. Enferm., Rio de Janeiro, 1, 2, 3, 1968.

2. FIGLIOLA, M. F. de C. Saúde Mental. Assessoria de Saúde Mental do Distrito de Saúde do Campo Limpo. Secretaria Municipal de Saúde. Prefeitura do Município de São Paulo, sem data. (mimeografado).

3. KURCGANT, P. et al. Administração de Enfermagem. São Paulo: EPU, 1991.

4. LOYOLA Miranda, C. M. Algumas questões sobre assistência de enfermagem psiquiátrica de qualidade. Cadernos IPUB, por uma assistência psiquiátrica em transformação. Rio de Janeiro, UFRJ, n. 3, p. 77-82, 1996.

5. NITTA, H. Plano de Trabalho. Assessoria de Saúde Mental do Campo Limpo. São Paulo: ASM-SMSP, 1996. (mimeografado).

6. PREFEITURA MUNICIPAL DE SĀO PAULO. Normatização de ações nos hospitais dia de saúde mental da Secretaria Municipal da Saúde. Programa de atenção à saúde, Centro de Organização da Atenção à Saúde, Secretaria Municipal da Saúde. São Paulo, 1995 (mimeografado).

7. PREFEITURA MUNICIPAL DE SÃO PAULO. Proposta de Operacionalização da atenção à saúde mental nos diversos serviços. Assessoria de Saúde Mental da Secretaria Municipal. São Paulo: ASM-SMSP, 1989. (mimeografado).

8.

Para compreender a atual política municipal de saúde mental do governo democrático e popular da cidade de São Paulo. Assessoria de Saúde Mental da Secretaria Municipal. São Paulo: ASM-SMSP, 1989. (mimeografado).

9. SCHECHTMAN, A. et al. Política de Saúde Mental no Brasil. Cadernos IPUB, Por uma assistência Psiquiátrica em transformação. Rio de Janeiro: Instituto de Psiquiatria - UFRJ, 1996, número 3.

10. TRAVELBEE, J. Intervención en Enfermería Psiquiatrica. Cali, Colombia: Talleres Graficos de Carvajal, 1979.

11. SOUZA, S. Nursing Assistance in the Mental Health Day Hospital - "Jardim Lidia". 